\title{
A Brief Look at Impact Investment
}

Richard Biggs(D3|ubilee Inc. Managing Director)

\section{Contents}

I. Introduction

II. A Brief History of Corporate Purpose

III. What is Impact Investment?

IV. Definition of Impact Investment

V. Impact Investment market size

VI. What is Impact?

VII. On Measuring Impact

VIII. The Impact Investment Ecosystem

IX. The Need for Collaborative Cooperation

$X$. Implications for Development Cooperation

\section{Introduction}

What will the world look like in fifty years' time? What is the legacy we will leave to our children? Will our children's children inherit a world bereft of social capital and ravaged by environmental crisis? Will the rapacious self-interest of the modern financial system and the guilty indifference of the post-modern individual ever serve the needs of the most vulnerable in society? Is there no way of harnessing the immense power of capitalism to solve some of these problems through market-based principles? 
There is a form of investment which takes into account the social1) impact of the investment as well as the financial return. This is called impact investing.

Some believe that impact investing is the evolutionary conclusion of tin-man capitalism and scarecrow philanthropy. It is still too early to know whether this is the case. But it is clear that investors around the world have a responsibility to look beyond straight financial returns to examine the externalities their investments are helping to scale. Every case of exploitation and injustice in the world is the result of narrow decision-making criteria. By expanding the corporate purpose beyond that of simple shareholder value creation, corporations and investors together can bring about a sustainable, equitable legacy for all our children.

\section{A Brief History of Corporate Purpose}

Impact investing and social entrepreneurship are not new concepts. Ever since the first corporation was established in 1600, there has been an implicit assumption that the corporation should enrich the lives of its customers and its employees, as well as its owners. This assumption was made explicit in Great Britain in the $19^{\text {th }}$ century, with factory owners acting on their convictions to improve the living conditions of their workers, sometimes at great cost to themselves.

The town of Saltaire in Northern England perfectly captures this social entrepreneurial spirit. Founded in 1851 as a "model village" (in that it was to be

1) For the purposes of this paper, social impact will be used to describe positive outcome to people and the environment. This is a necessary clarification as not everyone considers a positive outcome for the environment to be equivalent to a positive outcome for people, and will only consider environmental impact as social impact if the positive outcome for the environment leads directly to a positive outcome for people. 
a model for others to follow), Saltaire was conceived by wealthy industrialist and factory owner Titus Salt. The heart of the village was Salts Mill, a large textile mill which would create value and provide employment. But Titus Salt did not stop there. He went on to build top-class stone housing for his employees (the houses are still standing today), wash-houses with running tap water, bath-houses, a hospital and an institute for recreation and education, complete with library, reading room, concert hall, billiard room, science laboratory and gymnasium. The village had a school for the children of the workers, which cost $£ 7,000$ to build at the time or about $\$ 10$ million today.

제 I장

제I장

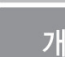

<lmage 1> Salts Mill
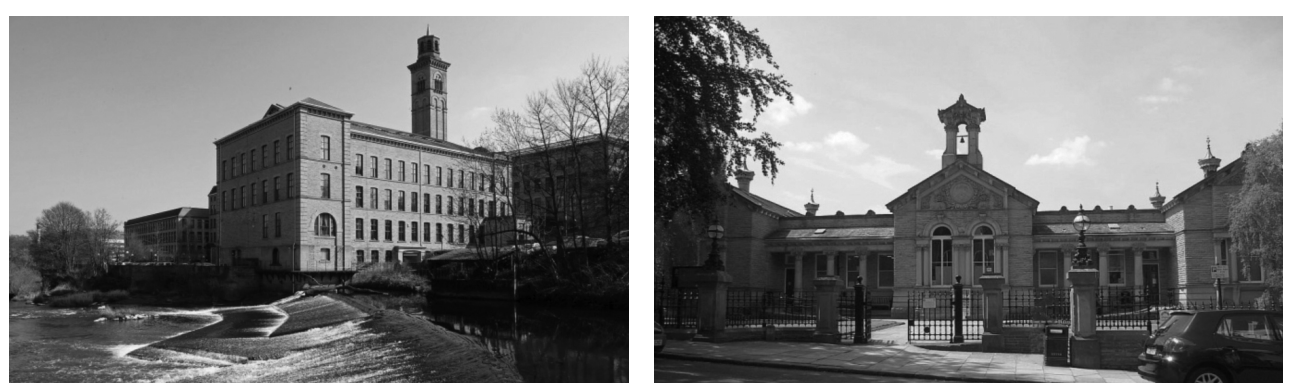

Source: The Victorian Web, www.victorianweb.org

The innovation and forward-thinking of such endeavors cannot easily be imagined. These innovations took place at a time when no women, and only the richest one-fifth of all men, had a right to vote. Most workers worked 14-16 hours a day in atrocious slum conditions. The application of the truck system was commonplace, whereby workers were paid in tokens which were only redeemable for goods at the factory-owned truck shop; the system was often abused and low-quality goods were often sold at inflated prices. In this era of rapacious and unregulated capitalism, socially-minded industrialists were hard to find, and were often ridiculed by other industrialists and members of the ruling class who felt threatened by the empowerment of the working class. 
The view that corporations were at least partially responsible for the welfare of its customers and employees was only thrown out of popular thought with the rise of neo-classical economic theory in the 1960 s and 1970s, where the purpose of a corporation was narrowly defined as the creation of shareholder value - that is to say, maximizing returns for shareholders regardless of the impact on the firm's other stakeholders. This recent definition of corporate purpose is now accepted as self-evident and axiomatic to such an extent that it is possible in some countries for the managers of a firm to be taken to court if they have engaged in activities that do not maximize the firm's profits (charitable giving, for instance).

Only since the 1990s has there been a shift in the general belief that corporate purpose should be something more than value creation for shareholders. The advent of terminology such as triple bottom-line, blended value and stakeholder value creation suggests a paradigm shift in our understanding of the role of the corporation in modern society. Impact investing is the logical inevitability of this transformation of thought - as the purpose of the corporation shifts to accommodate many stakeholders, so the purpose of investment shifts to accommodate the impact on these stakeholders. 


\section{What is Impact Investment?}

Impact Investment is a recent moniker applied to an age old concept: investment that considers the wider impact on society and the environment as well as the financial merits of the investment. Of course, investment means different things to different people; governments invest, non-profits invest, corporates and individuals all invest with different motives and through different investment instruments. As such, there is a spectrum of impact investing activities depending on the ultimate aim of the investment.

$\langle$ Chart 1> Impact Investment Spectrum

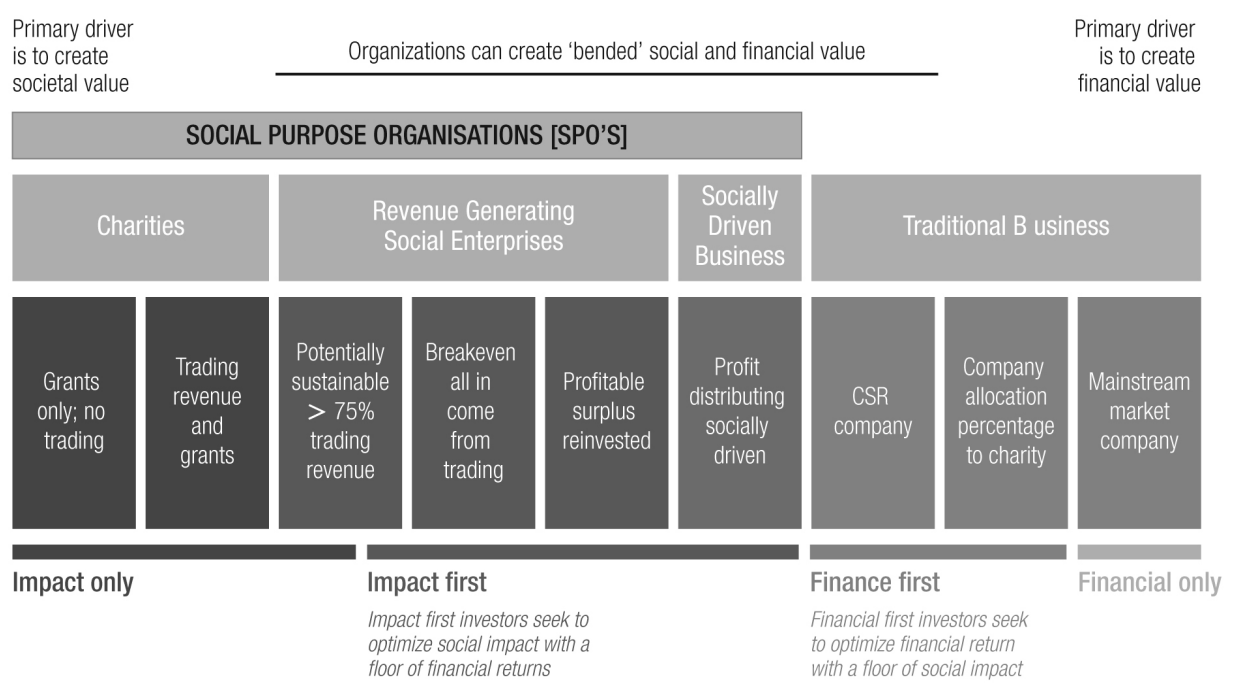

Source: Shaerpa, www.shaerpa.org/en/venture-philanthropy/

In the above diagram, impact investment will usually be understood to cover the "Impact-first" and "Finance-first" portions of the spectrum, essentially meaning that impact investing covers everything from straight philanthropy to financial-only investment. This extremely broad understanding of impact investment raises many problems, not the least of which being that two funds or firms that call themselves impact investors may have unrecognizably different 
investment philosophies. This can ultimately hinder mutual respect and cooperation in the sector.

It should be noted that the spectrum in the above diagram is organized on a one-dimensional social return/financial return axis. It is natural to believe that there is a direct tradeoff between the two; that by increasing financial return, you necessarily have to sacrifice social return, and vice versa. And at some level, this is true: if it costs money to pollute less, you cannot increase shareholder value and environmental value simultaneously; in the same way, you cannot increase worker salaries and company profits at the same time. But in a wider context, there are plenty of social enterprises extant whose social mission is fully integrated with their financial mission; if one goes up, the other will as well. As such, it is usually more informative to think of impact investment as occurring in a two-dimensional space where a certain minimum of social impact and financial return are simultaneously achieved. The companies are not just the best in the world, they are "Best For the World".

$\langle$ Chart 2〉 Best for the World

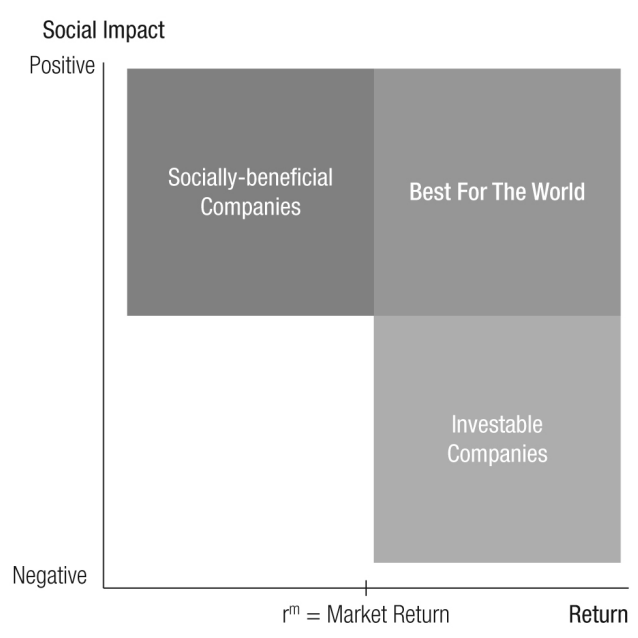

Source: D3Jubilee 
It is also important to distinguish impact investment from some other buzzwords that have become popular over the past decade. Firstly, impact investment is not the same as socially responsible investment (SRI). This is because SRI for the most part is focused on companies that minimize the negative impacts of doing business, which is distinct from an organization that actively promotes benefit to society. Impact investment is also not the same as corporate social responsibility (CSR). Although there may be some overlap, CSR usually takes the form of a socially-beneficial module that is attached to the core business. The module can easily be detached from the business, and particularly in times of financial tightening, the social mission can be thrown out completely. In contrast, the core business of a social enterprise is the social benefit itself and cannot be detached - this is called "mission lock".

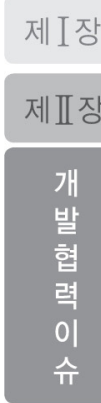

Finally, we are now seeing impact investments as not only spanning the dichotomy between philanthropy and financial investments, but increasingly seen by governments as efficient mechanisms for the delivery of social services. The "Third Way" concept adopted by Tony Blair's government in the late 1990's altered the discussion concerning government's role in society, and has propelled the UK government as a key leader and innovator in the impact investment arena. There is a definite role the government can play in encouraging and participating in impact investment.

\section{Definition of Impact Investment}

By seeking to simultaneously satisfy the twin objectives of financial returns and social outcomes, impact investment necessarily overlaps with other forms of investment and philanthropy. It is therefore very difficult to define impact investment as everyone has slightly different expectations and understanding of the nature of impact investment. The Global Impact Investing Network (GIIN) uses the following definition: 
Impact investments are investments made into companies, organizations, and funds with the intention to generate a measurable, beneficial social and environmental impact alongside a financial return.

The key concepts behind this definition are intentionality, measurability, and sustainability.

- Intentionality. Does it matter whether the organization intentionally generates social impact? Isn't it enough the social impact is being generated? While no-one can argue with the value of an organization that generates social impact as a by-product, intentionality comes to the fore when the organization changes direction. The best impact investors will reward mission lock, or some form of mechanism that will hold the organization to an impact-creating course.

- Measurability. As the late great Peter Drucker said, "You can't manage what you can't measure." If an impact organisation is not measuring its impact, it is not serious about the impact it generates, and therefore it is not an impact organisation. Impact measurement is crucial to performance evaluation, mission accountability and even funding.

- Sustainability. As indicated above, impact investment seeks to simultaneously generate financial returns for investors while providing socially beneficial outcomes for its target stakeholders. Financial objectives allow for sustainability for the organization, while social objectives allow for sustainability for society.

A caveat: while many players in the sector would agree broadly with GIIN's definition and assent to the three principles above, these in no way form a universally-accepted definition. Both impact and investment mean different things to different people, and there is still a great deal of confusion among practitioners concerning the nature and definition of impact investment. 
Some would label impact investment as any kind of funding for social enterprises in the broadest sense, including funding for non-profits or even quasi-governmental organisations. While such broad-based definitions are understandable in an effort to evaluate the quantity and quality of impact investment as a whole, it is generally not helpful to expand definitions so broadly that they become effectively meaningless. For the purposes of this report, when we speak of impact investing, we are speaking of investment (usually in the form of debt or equity) that seeks, at the very least, the return of principal while generating positive social value.

제 I장

제I장

\section{개}

\section{Impact Investment market size}

There have been many attempts to quantify the size of the global impact investment sector, but the decentralized nature of impact investment and difficulties of definition have made this a challenging task. Nevertheless, efforts by leading global institutions in the last few years are helping to shape the picture. In 2009, the Monitor Institute estimated that the global impact investment market could reach $\$ 500$ billion by 2020 , based on $1 \%$ of total managed assets of $\$ 50$ trillion being allocated for impact investment. In their seminal 2010 report "Impact Investments: An Emerging Asset Class", JP Morgan and the Rockefeller Foundation sized the bottom-of-the-pyramid market opportunity across five sectors and estimated that the impact investment sector could reach $\$ 400$ billion to $\$ 1$ trillion by 2020. In 2012, the Calvert Foundation estimated an impact investment market potential of $\$ 650$ billion through a survey of investment managers.

In a 2012 JP Morgan survey of 99 investment managers, the respondents claimed that a total $\$ 9$ billion had been committed for impact investment in 2013. Given that there are around 250 global impact investing funds, this gives a current conservative market size of around $\$ 25$ billion. This is likely to be a 
gross underestimate as it only accounts for certain asset classes such as private equity and venture capital, to the exclusion of green bonds, infrastructure investment, community development finance, social impact bonds, etc. Furthermore, leading microfinance organization CGAP estimated 2011 cross-border funders committed at least $\$ 25$ billion to microfinance and financial services to the poor. While not all of these can be classed as impact investments, the current size of the global impact investment market is more likely to be closer to $\$ 50$ billion.

<Chart 3> Impact Investment Market Size estimates

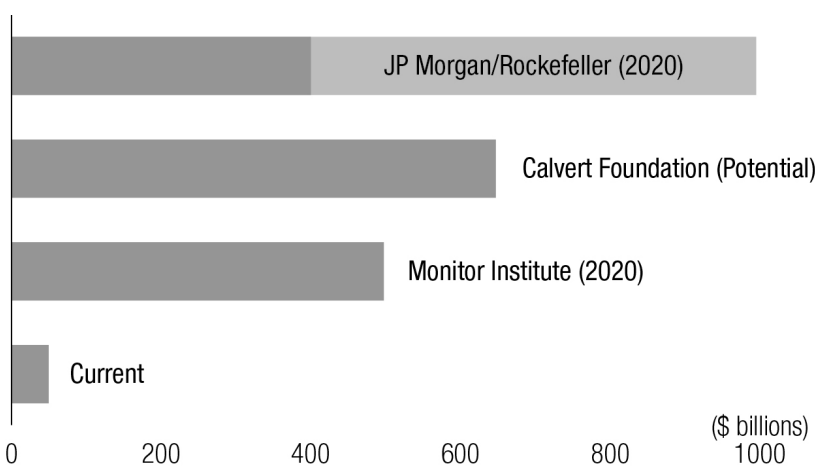

Source: Various

It is clear from this chart that the impact investment sector is very young and has a long way to go. It remains to be seen whether the long-term expectations of these institutions will be realized within the time frame, or ever. What is clear is that even at current levels, so much can be done. If \$50 billion is the size of the global impact investment market, it is the amount that Europeans spend on cigarettes every year. Against this, the UNDP estimates that everyone in the world can be provided with basic and reproductive health for \$25 billion, with a further \$15 billion bringing access to clean water and basic education for everyone on the plant who doesn't have it yet. The world's problems are not too big to solve, and the impact investment industry does not have to become a trillion-dollar sector for there to be real changes in the world. 


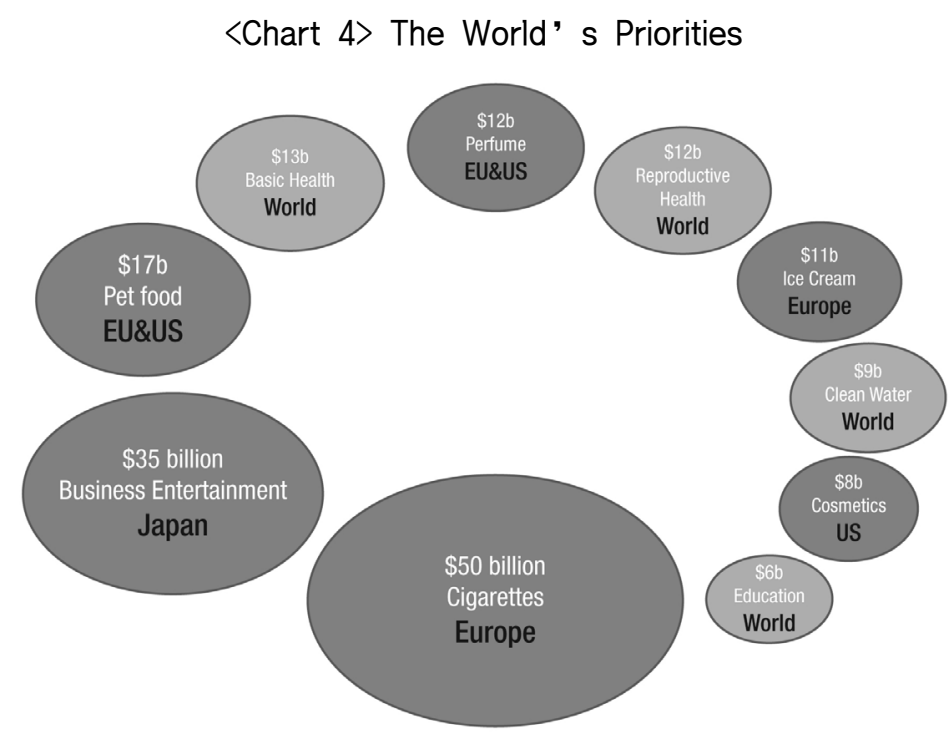

Source: UNDP Human Development Report 1998

제 I장

제I장

\section{개}

Impact is the externality generated by an organisation in the course of doing business. Clearly, impact can be positive, such as the long-term health benefits of supplying clean water, or negative in cases such as pollution. It is also clear that every organization produces impact, whether positive or negative, whether it is measured or not, or even whether it is intentional or not. These are the distinctions that differentiate an entrepreneur from a social entrepreneur and an investor from an impact investor.

Impact is also generated in stages. There is the direct, first-order impact of an organization's activities, which can often lead to second- or third-order impact. It is usually the case that second- or third-order impact addresses the problem the organization seeks to solve, and most impact organizations use a basic theory of change model to define and clarify the problem and the solution. 
<Chart 5> Basic Impact Theory of Change Model

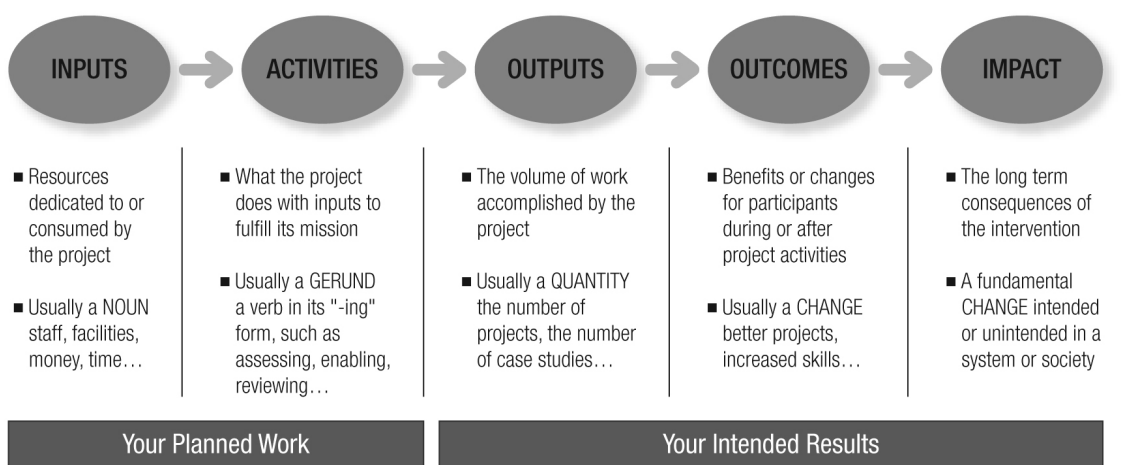

The first-order impact can be the output of the organisation itself, although more commonly it will be an outcome of the organization's activities. The ultimate impact of the organisation will usually be a result of the first-order impact, or outcome, of the organization's activities. Meaningful impact measurement will capture all the degrees of impact, focusing on the outcomes and ultimate impact as much as possible. However, the further away one gets from the the organisation's direct output, the more difficult it is for the organization to measure: the outcomes and impact may take place in remote locations, or the impact may be dispersed among large numbers of people, or other factors may have contributed to the outcome and impact and it is impossible to isolate the organization's contribution to the ultimate impact.

To illustrate this, we can use an example. As an organisation, UK-based The Big Issue seeks to eradicate homelessness by providing income-earning opportunities to homeless and otherwise vulnerable populations. The Big Issue does this by publishing a magazine that is sold by homeless people - around $50 \%$ of the revenue generated by the seller goes back to the Big Issue organisation, and the remainder stays with the seller. The idea is that, with a stable income, the homeless person will ultimately be able to afford a home. The organization also provides counselling and basic support to the sellers. 
From the point of view of the organization, the Inputs and Outputs are clear. The Big Issue needs to employ staff and operate facilities (Inputs). With these inputs, the organization publishes the magazine and supports the sellers (Activities). As a result, a number of magazines are sold and a number of sellers are counselled every month (Ouputs). Quite straightforward, but so far we have learned little about the effectiveness of The Big Issue at tackling the core problem of homelessness.

From here we can move to the Outcomes. The outcome of magazines being sold is the income earned by the sellers themselves, and the outcome of the counselling activities are improvements in the mental health of the sellers. But neither of these are relevant to the ultimate goal of reduction in the number of homeless people, and therefore the organisation will need to look at the impact of these outcomes which is the number of sellers who, as a result of selling the magazine, have been housed and are no longer homeless. This can then be compared to changes in the number of homeless of that city to determine the ultimate effectiveness of the Big Issue at tackling homelessness.

This is a very straightforward example where there are clear links between the outputs and the impact, and where the impact is binary (the seller is either housed or is still homeless) and therefore easy to measure. It is much more difficult to measure the improvement on household welfare through the provision of basic services such as education, healthcare or clean water where the links between the outputs and impact are much more vague.

It is still more difficult, if not impossible, to compare the impact across different fields: for instance, how can one compare the impact of post-natal healthcare that reduces infant mortality rates to female education that is proven to reduce birth rates and increase per capita income? Given the limited resources available for impact investment, such questions have to be addressed when determining investment priorities. 
To make sense of these questions, impact organizations can look at the nature of the impact which can be broken down into three dimensions:

- Breadth - how many people are reached. This is all about scale. 3.5 billion people in world live in poverty, and scaleable interventions that can reach millions of people are necessary to make a difference.

- Focus - how necessary is the intervention. This is all about priority. Given the limited resources available making lasting social change, it is important to allocate resources to the most desperate first. This will usually mean the most poor on the planet, but with local impact investment can mean a focus on the most vulnerable in society.

- Depth - how much the intervention impacts household wellbeing. This is all about substance. Some interventions can reach millions of people but not make any meaningful difference in their lives. Depth of impact looks at the real change at the household level that results from the intervention.

To be an impact organisation, at least two of these dimensions should be addressed simultaneously, and ideally the organisation should seek to be at the intersection of all three, the "Sweet Spot", where scaled, meaningful intervention is being delivered to the people who need it most. 
$<$ Chart 6> The Three Dimensions of Impact

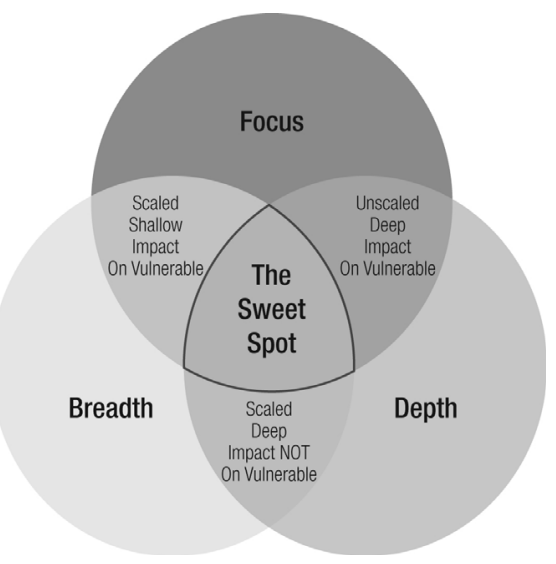

Source: Acumen

Breadth and Focus are easy concepts to understand, and there is little argument about the nature of these dimensions. Both concepts are possible to link directly to the organisation's activites, and are easy to measure. Depth of impact, however, is a much more complicated dimension that requires much subjective evaluation. As such, there is a lot of disagreement over what exactly constitutes depth of impact - for instance, there is particular disagreement over sharing economy models such as Airbnb or Zipcar.

\section{On Measuring Impact}

Everyone knows that externalities are difficult to measure - indeed, measurability, or the lack thereof, is a key characteristic of an externality. When we start talking about the social externalities, the case becomes even more diffcult as the highly unpalatable situation of attempting to ascribe a value to human well-being, or even human life, become real and necessary. Even when it seems to be possible to quantify the impact of an intervention, as in the case of education initiatives, the significant time periods involved in the delivery of the intervention and the receipt of the benefits make it very hard to directly 
attribute the benefit to the intervention. And then there is the question of whether some social externalities constitute social impact at all.

For these reasons, social impact is very difficult to evaluate, and almost impossible to quantify. The heroic efforts of the SROI Network to quantify social impact by looking at the Social Return on Investment of an organization have not taken off because of disagreement within the industry over the validity of the proposition that one can sum up all the value, both social and financial, into a single quantitative ratio.

Impact measurement has rather moved towards a more qualitative accounting of an organization's social impact. The Global Impact Investing Rating System (GIIRS) assesses an organization's impact based on the four areas of Governance, Workers, Environment and Community. Points are attributed to each of the areas, and an overall rating ( 1 to 5 star) is given to the organisation. GIIRS is rapidly becoming a standard for impact assessment worldwide on account of its flexibility, ease of use and affordability.

Some impact assessment methodologies are as follows:

- GIIRS. Developed by B Lab with support from GIIN. Uses the IRIS taxonomy which defines impact outcomes. The GIIRS assessment is a necessary step in achieving the B Corp certification, also administered by B Lab.

- SROI. A framework based on social generally accepted accounting principles (SGAAP) that identifies stakeholders and assesses what would have happened in the absence of the organization's work. SROI accounts for the social, environmental, and economic value of an organizations's outcomes. 
- Progress out of Poverty Index (PPI). Managed by the Grameen Foundation, the index uses a simple questionnaire about a household's characteristics and asset ownership to help identify and classify an organizations' clients.

- PULSE/B Analytics. Originally developed by Acumen Fund, PULSE was designed to help investors collect, manage, and report on impact portfolio data. In 2013, PULSE was incorporated into the B Anaytics platform that enables impact investors to measure, benchmark and report on the impact of their portfolios.

- CARS. Developed by the Opportunity Finance Network, the CDFI Assessment and Ratings System is similar to GIIRS in that it is a ratings system (AAA through to $B$ ) for CDFls (community development finance institutions).

- KIIA. The Korea Integrated Impact Analytics is a third party initiative jointly developed by Impact Sqare and Sustinvest. Similarly to SROI, the methodology seeks to quantify social impact in a qualitative and quantitative way. The initiative was designed to address the particular nature of the Korean social investment space with its focus on employment of vulnerable populations.

Affordability is key because transactions costs are already very high for impact investment deals. Given deal sizes averaging less than \$2 million, there is already little headroom for a level of due diligence that would be expected of a mainstream investment deal. An impact investment, however, needs to undergo due diligence on the impact side as well. This is a cost that is not easily borne by the investor or the entrepreneur, particularly in complex deals or where impact is difficult to measure. An impact assessment methodology that is quick and cheap is ideal for bringing down transaction costs and facilitating deal flow.

An overwhelming majority of investors consider impact measurement to be important. In JP Morgan's 2012 survey of institutional impact investors, 96\% of 
respondents said that they use metrics to measure social and environmental impact, and $70 \%$ feel that standardized impact metrics are "Important" or "Very Important" to the development of the industry. More strikingly, $82 \%$ of fund managers believe that measuring impact is necessary or important to raising capital.

Having said that, the high costs involved with impact measurement means that in many cases only a cursory effort might be made for assessing impact, and assessment methodologies might not be more sophisticated than "I know impact when I see it".

<Chart 7> The Importance of Standardized Impact Metrics to industry development

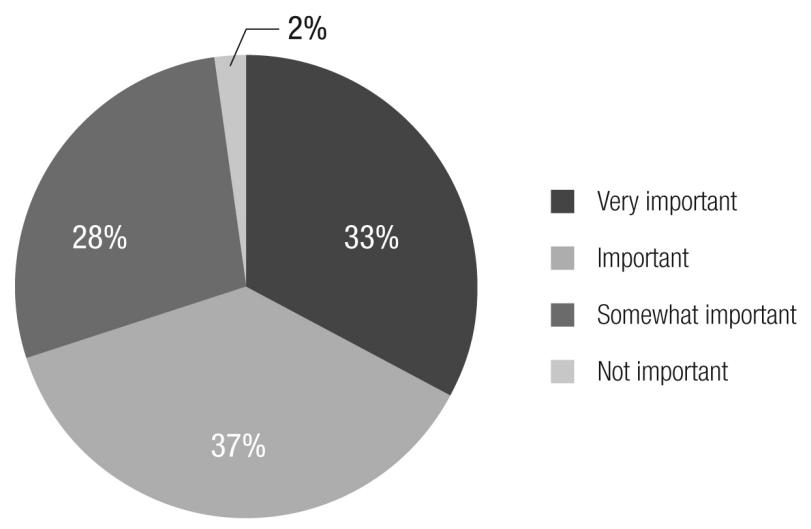

Source: "Perspectives on Progress" , JP Morgan/GIIN, 2013 
<Chart 8> The Role of Impact Measurement in raising capital for fund managers

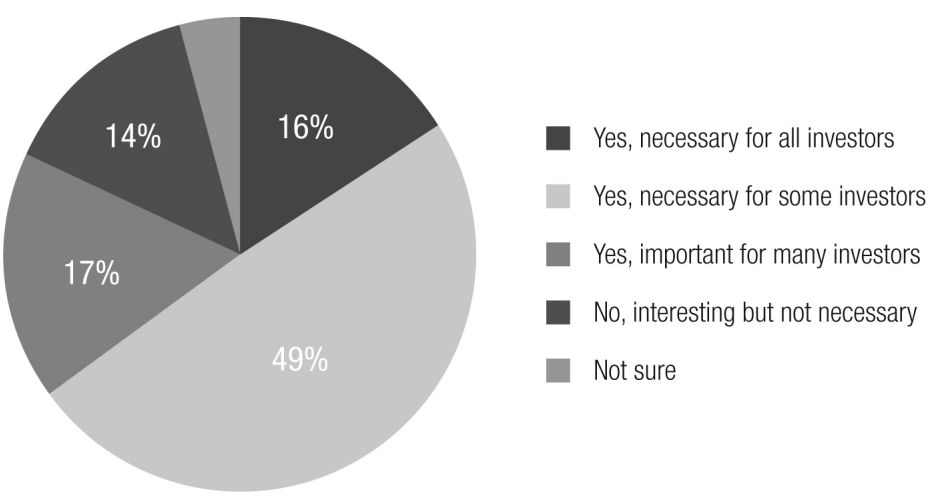

Source: “Perspectives on Progress" , JP Morgan/GIIN, 2013

\section{제 I장 \\ 제I장} either case there must be a supporting ecosystem to facilitate transactions and reduce costs.

In the ecosystem, it is of course vital to have investors and entrepreneurs. To facilitate the transactions, there must be financial intermediaries - corporate advisors on the one hand to support the social entrepreneurs raise capital, and impact investment funds to pool investors and reduce costs. Accelerators are key players as they incubate and fund social ventures from seed stage to maturity, and industry associations need to define standardized metrics and agree on reporting principles to measure social as well as financial return. All this will be underscored by organizations offering research and due diligence to ensure transparency, and the government providing the regulatory framework and financial support for the sector. 
$\langle$ Chart 9> The Impact Investment Ecosystem

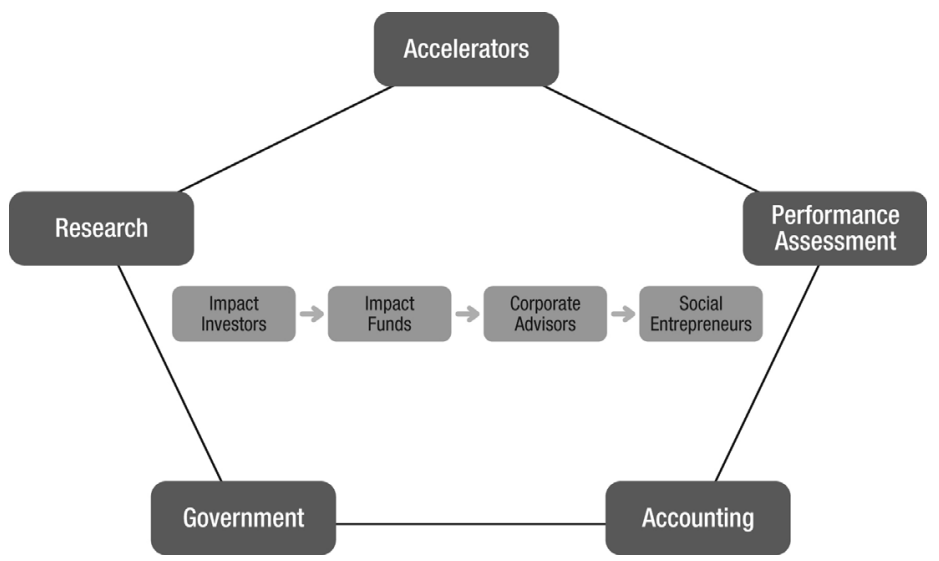

Source: D3Jubilee

Without exception, all the players in the impact investment ecosystem are underdeveloped, some more than others. There are plenty of social entrepreneurs out there, but many lack the technical rigor and the business scale required to absorb capital. On the flip side there are many potential impact investors, but they are constrained by any number of factors such as access to meaningful amounts of capital, investment mandates, fiduciary responsibility, or even just conservatism or prejudice.

The greater problem comes from the remaining players in the ecosystem they don't exist in the scale needed to provide meaningful support and efficient infrastructure. According to the Monitor Institute, "the market is structured around a history of bifurcation between philanthropy (for impact) and investment (for returns)". And, "the compensation system for traditional intermediaries also impedes getting small deals done which may have less lucrative fees". All this results in a bottleneck between the investors and the entrepreneurs - the money is not getting through. Nonetheless, there are pioneers who are seeking to build the necessary infrastructure by innovating new models and metrics. 


\section{Impact Investors}

Impact investors come in all shapes and sizes from the executive assistant in New York placing \$100 with Kiva.org to foundations with \$100 million and more under management. At the individual level, impact investors are mainly comprised of high net worth individuals (those with more than \$1 million in investable assets), family offices and the ultra-rich such as eBay founder Pierre Omidyar (Omidyar Network). At the institutional level, the usual providers of mainstream capital such as pension funds and insurance companies are joined by foundations and development finance institutions.

$\langle$ Chart 10> Capital Flows in the Impact Investment Ecosystem

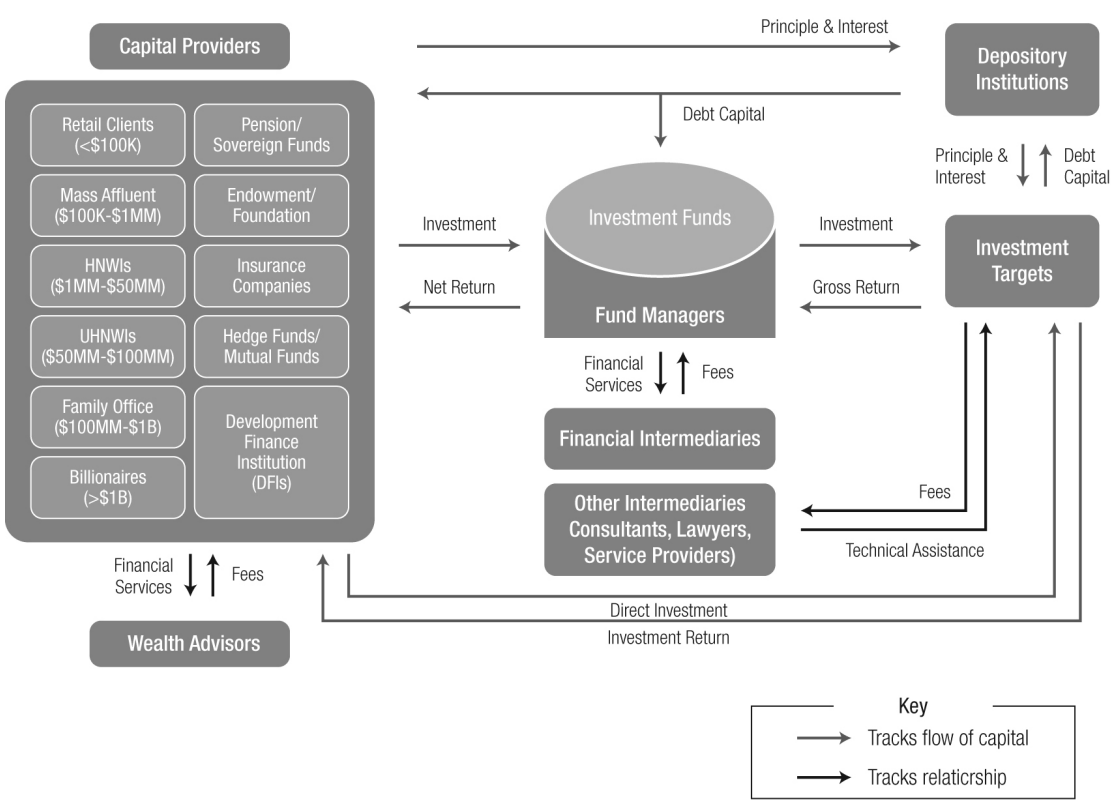

Source: "From the Margins to the Mainstream" , World Economic Forum, 2013

As seen in the preceding chart, impact investment funds occupy centre stage in driving impact capital flows. It is estimated that funds raise at least \$25 billion every year for allocation into impact deals. According to JP Morgan's 2013 
survey, family offices and high net worth individuals lead the charge in funding the impact investment funds, closely followed by development finance institutions.

<Chart 11> Sources of funding for impact investment funds

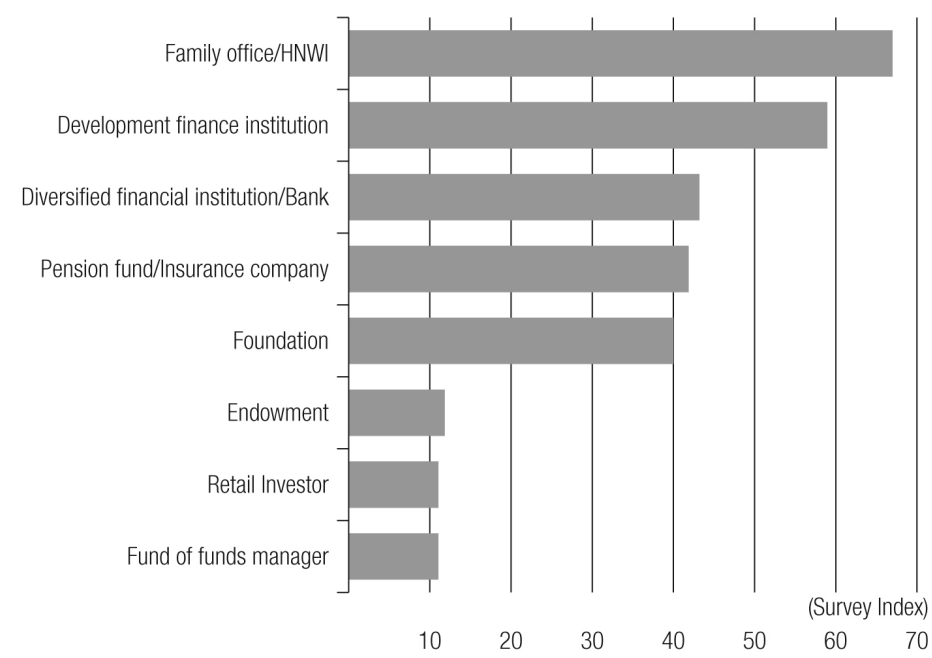

Source: "Perspectives on Progress" , JP Morgan/GIIN, 2013

\section{Corporate Advisors}

The term 'corporate advisor' is used to denote the role of a traditional investment bank in putting deals together. Others may prefer the term 'financial intermediary'. In the most basic sense, corporate advisors are necessary to help entrepreneurs raise capital. But to accomplish this, corporate advisors may have to devise and market new instruments and structures to efficiently complete the transaction.

Social Finance in the UK has risen to prominence in recent years due to their central role in creating the world's first Social Impact Bond. These are essentially a contract for the government to reimburse investors of service providers if certain targets are met. The first SIB was launched in the UK in 2010, and 
generated much excitement in the social finance sector. In August 2012, Goldman Sachs invested in a $\$ 9.6$ million bond to reduce recidivism (criminal re-offending rates) in New York. Similar projects are being undertaken in Australia, and are being examined by many governments around the world.

But Social Finance typifies the problems faced by corporate advisors in the impact investment arena. The UK SIB took 12 professionals from Social Finance over 2 years to put together (perhaps over GBP 1 million in salaries alone), and they received around GBP 0.5 million in pro bono legal services. Against this, the SIB was issued at a value of GBP 5 million, of which Social Finance was entitled to $2 \%$ in service fees. As such, they received GBP 100,000 for a deal that would have cost them at least GBP 1.5 million. Such is the problem facing intermediaries in the impact investment sector - the need to provide investment banking-grade services but only receiving a fraction of their value because of the scale of the deals. Social Finance financed this project with grants from the UK government.

\section{Accelerators}

Accelerators play a key role in the impact investment chain. Essentially an upgrade of traditional venture incubators, accelerators "accelerate" the scaling of social enterprises through the provision of funding, management support and sometimes office space. Part-investment fund, part-private equity, part-incubator, accelerators can offer a variety of innovative services in return for an equity stake in the social enterprise.

Greenstart is based in San Francisco and is focused on 'digital cleantech' companies that use software to provide a product or service that expands the use of clean energy or reduces the use of dirty energy. Greenstart currently works with about 12 startups a year, offering them a 3-month program within 
the Greenstart office in San Francisco. Greenstart will invest $\$ 15,000$ for between $2-9 \%$ of equity, and offer up to $\$ 70,000$ of design services as part of the package. There is an option for the startups to take on a $\$ 100,000$ convertible note. When the 3-month program is complete, the startups will move out but will remain part of the Greenstart family, with access to mentoring support.

The key differentiating factor of Greenstart is their focus on design. Their Startup Design program concentrates on "making major progress in the four areas that matter most to a startup's success: Business Model, UX (user experience), Brand and Capital."

\section{Performance Assessment}

There is clearly a need for a third-party standard for defining, measuring and comparing performance, particularly social impact. This standard will not only support impact investors in making their investment decisions, but it should also reduce transaction costs, and provide metrics for social entrepreneurs to identify areas for improvement.

GIIRS (Global Impact Investing Ratings System), a project of B Lab in the US, seeks to provide such a standard. GIIRS assesses the social and environmental impact of companies and funds using a ratings approach which can be used to by investors and entrepreneurs alike. GIIRS achieves this through a thorough assessment of all the proactive, positive social impact of a company or fund, prioritizing action over intent, rewarding formal written policies of social performance and leveraging third-party certifications such as Fair-Trade or USDA Organic. The result is a rating for overall performance, as well as ratings for individual areas within the company, which allow both investors and entrepreneurs to see areas for improvement within the company while enabling comparisons to other companies in the same industry or region. 
The GIIRS rating does not seek to put a financial value on social impact, and therefore is not conducive to answering questions about the tradeoff between social and financial returns. Nevertheless, ratings are an innovative application common practice in the investment world, and a necessary part of the impact investment ecosystem.

\section{Accounting \& Reporting}

Without a common language for what social and environmental impact means, all forms of measuring and comparing become very expensive and probably meaningless. As one impact investor put it, "It takes consistency in language to create a business. The biggest challenge is to have a coherent set of terms and phrases that are clearly defined and have clear meaning."

IRIS (Impact Reporting \& Investment Standards), initiated by The Rockefeller Foundation, Acumen Fund and B Lab, is creating a common framework for defining and reporting the performance of impact capital. In 2009 IRIS became an initiative of GIIN (Global Impact Investing Network), an industry group purposed to increase the scale and effectiveness of impact investing. It is designed to enable communication and comparison among all the players in the impact investment arena by providing a common reporting language for impact-related terms and metrics. For example, IRIS defines the item "Hazardous Waste avoided" as "Hazardous waste avoided based on refurbishing/reusing/recycling, during the reporting period”, further defining “Hazardous Waste" with UNEP's definition: "Refuse that could present dangers through the contamination and pollution of the environment. It requires special disposal techniques to make it harmless or less dangerous."

The IRIS framework is very powerful, but is only as useful as its uptake. If everyone in the impact investment adopts the terms and definitions laid out by 
IRIS, communication will be enhanced and transaction costs should decline. IRIS has already been adopted by GIIRS, and its relationship to GIIN should ensure that it becomes the most widely-adopted system in the impact investment arena.

\section{Research}

Independent research is vital to the impact investment arena for several reasons. Company research can bring some much-needed rigor to the passion and drive of the entrepreneurs, enhancing the entrepreneurs' management capacities as well as giving investors the opportunity to thoroughly assess potential targets. This should naturally reduce transaction costs if done at scale. Industry research is vital for the sharing of best practice among social entrepreneurs who are so dispersed across so many fields in such a multitude of locations that they find it difficult to engage with each other, while investors need to know the size, shape, structure of their target sectors and the pattern of returns across sectors. Theoretical research into the validity of impact investment is critical to policy makers.

At present much of the theoretical and industry research is being conducted by academia. Many universities now boast dedicated social enterprise centers, such as the Skoll Centre for Social Entrepreneurship at Oxford University. Management consulting firms are also in on the action, with McKinsey and the Monitor Institute of the Monitor Group leading the way.

At the company level, however, there is little quality research. The same problems faced by intermediaries are there for research firms - that is, lack of funds. The costs involved in producing good research far outweigh the revenue from the product. In the absence of support from philanthropy or the state, it seems likely that quality research at the company level will be prohibitively expensive. 


\section{Government}

The government plays a critical role in the impact investment arena as a provider of social services to be invested in by the private sector, as a client of services provided by social enterprises, and as regulator and policy maker. It is vital for the government to be at the forefront of this field where financial support is necessary for all the players who are together seeking to solve problems that would otherwise fall into the government's lap.

제 I장

제I장

Big Society Capital is an independent financial institution in the UK funded by dormant bank deposits and investments from 4 leading banks. Its mission is to develop and shape a sustainable social investment market in the UK by investing directly into social investment financial intermediaries rather than entrepreneurs or non-profits. By supporting financial intermediaries to grow and become more sustainable, Big Society Capital hopes to ease the investment bottleneck between impact investors and social entrepreneurs.

<lmage 3> Mapping the Impact Investing Industry

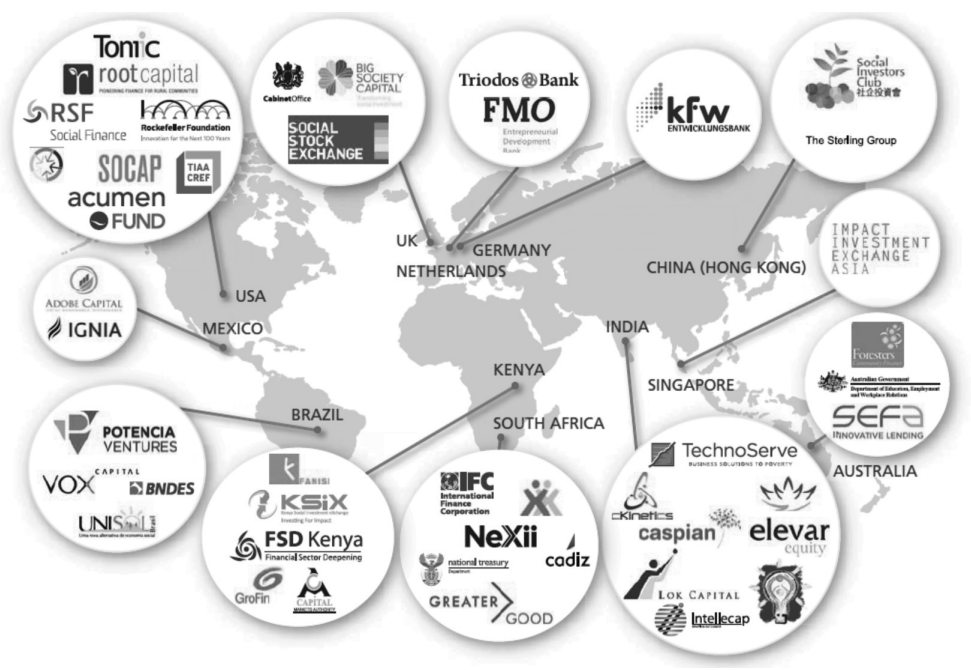

Source: "Accelerating Impact" , The Rockefeller Foundation, 2012 


\section{The need for Cooperative Collaboration}

There are social problems all around, whether in London or in Lagos. Some of these problems are being addressed by government and others by non-profits. But there are problems in places in the world where governments cannot reach, and other problems that are simply too big for governments and non-profits to tackle. Given the pervasive and ubiquitous nature of private enterprise, and the vast pools of capital that private investors can access, impact investment must be seriously considered as a potential solution to the world's societal and environmental ills.

Impact investment has grown from humble beginnings to the multi-billion dollar industry that it is today. If it is to become a trillion-dollar industry and really make a difference in the world, there needs to be much more intentional collaboration among the key players in the industry - the investors, the entrepreneurs, the intermediaries and governments around the world. Each player has a responsibility to find areas of common ground and channels of communication that can bridge the gaps between sectors, methodologies, mindsets and priorities. In the spirit of responsibility and innovation, each player must look less to short-term personal gain and more to broad-based cooperative collaboration that can enrich the lives of the most vulnerable and expand the sustainability of the world we live in.

\section{Implications for Development Cooperation}

There are many roles that governments can play in the impact investment space, including structuring appropriate regulations, devising tax and subsidy systems that more closely reflect the social and environmental impact of social enterprises and impact investors, facilitate dialogue between the key players in the space, and play an active role in de-risking investments. 
Of these, de-risking is the most important field for Development Finance Institutions (DFIs) and Development Cooperation organizations. Impact investments are necessarily made into areas that are not traditionally covered by mainstream financial institutions (banks, funds, etc) - this is very telling because mainstream finance would not lose the opportunity to make a buck if there were significant returns to be had for a reasonable level of risk. We know that impact investments can yield significant returns, and so the reason mainstream finance is not engaged is because of the unacceptable level of risk.

제 I장

제I장

Risk comes in many forms, but for social enterprises, investment risk arises mainly from untried business models, lack of human capital, lack of scale, and systemic factors such as political or climatic risk. Development finance can play a huge role in de-risking impact investments, particularly in the poorest developing countries where systemic risk is highest. There are three ways in which development finance can play this critical role:

(a) Provide guarantees so that impact investment funds can benefit from a fiscal safety net. To accelerate the deployment of capital into the countries and sectors that are the most underserved, governments and DFIs can provide loan guarantees to reduce the lenders' exposure to risk.

(b) Take a subordinate position in a layered-structured fund. Governments and foundations are sometimes willing to accept first loss on an investment to protect the for-profit impact investor from downside risk. First-loss capital is catalytic in that in can bring about an investment which may not have happened without the first-loss buffer.

(c) Establish a pool of capital for market builders, first-time funds and early-stage enterprises. Through direct investment in intermediaries, funds and enterprises, governments and DFls can catalyse the establishment of an impact investment ecosystem. This is exemplified by the UK government's establishment of Big Society Capital which invests in social 
finance intermediaries. OPIC of the US provided $\$ 285$ million of anchor finance to 6 impact investment funds so that the funds could raise an additional \$875 million from mainstream investors. In frontier markets, investments can be made to build capacity of local entrepreneurs, with the ultimate aim of readying them to absorb commercial capital. 